\title{
Gains from Synchronization
}

\author{
by William A. Barnett and Mehmet Dalkir \\ University of Kansas,
}

March 30, 2005

\begin{abstract}
This paper investigates the transmission mechanisms of noise and volatility between economies through trade links, and the effects of synchronization on business cycles. We investigate the transmission of outside noise and the fluctuations that the noise generates. We identify conditions under which international economic links reduce the economic output noise emanating from noise within the individual economies. Under certain conditions, devaluation of a country's currency causes reduction in the business cycle noise and volatility as seen by that country's exporters, while increased valuation of a country's currency produces higher noise and volatility, as seen by the country's importers.
\end{abstract}

Keywords: business cycles, synchronization, international trade, stochastic systems. 


\section{Introduction}

From a dynamical systems perspective, this paper provides a rigorous analysis of synchronization of economies. The relevant literature contains two unanswered questions that we address: (1) identification of the role of trade links on the transmission of noise and thereby on increased unpredictability and (2) whether or not synchronization facilitates the reduction of noise and volatility in economies connected with trade links. We use three models to investigate the effect of trade on the transmission of noise. The first model is a linear stochastic differential equations system. The second model is a nonlinear stochastic equation system to account for changing trade links between countries. These two models assume that the economies are already synchronized. The third model enables us to investigate a case in which the economies are not fully synchronized. In this case, we find that partial synchronization increases the noise in both economies' business cycles, relative to that noise under perfect synchronization.

The models demonstrate that there are two effects of external linkages across countries: (1) generating predictable cycles in the domestic economy, while reducing random noise within the domestic economy, and (2) transmitting additional noise from the outside world into the domestic economy. In a two country model, we show that the exporter country benefits, through decreased noise and fluctuations, from devaluating its currency, whereas the importer country does not benefit, in terms of noise and fluctuations, from increased valuation of their currency.

In the economics literature, the concept of synchronization has been identified with correlation between economic aggregates. However, two deterministic periodic series may yield a correlation coefficient of less than one, while two deterministic time-trend series that are monotonically increasing or decreasing can produce a correlation coefficient of one. In the systems theory literature, any two deterministic series that have a constant phase difference in time should be denoted as fully synchronized. An example is the two monotonic series, having phase difference zero. From our point of view, two economies will be considered as fully synchronized during a long period of time, if the time lag between their activity peaks is constant during that time period. Having analyzed the two country case, we extend to the general multicountry case. In this general case, we focus on the possibility that linkage across countries could cause domestic fluctuations to vanish altogether. In the systems theory literature, this phenomenon is called "amplitude-death." We find that the possibility of taming fluctuations depends on the level of synchronization across countries.

The paper is organized as follows. Section 2 presents three alternative 2-country models that exhibit cycles. These models are used as base models to explore transmission of noise among economies. Section 3 generalizes to more than two countries, and derives the conditions under which all business cycles vanish. Through that derivation, section 3 is differs from section 2. In particular, section 3 seeks conditions under which fluctuations are wiped 
out altogether and investigates the depth of cycles, whereas section 2 derives exchange rate policies to minimize the noise in domestic output cycles and investigates the predictability of cycles. Section 4 concludes.

\section{Endogenous and Exogenous Cycles of Coupled System Pairs}

Dynamic economic models are usually in the form of first order difference or differential equations systems. A reason is the difficulties in interpreting second order derivatives (i.e., accelerations) in economics. However, much of the systems-theoretic literature on fluctuations requires second or higher-order differential equations. A way to circumvent this wedge between economics and systems theory is to model a number of interconnected economies or subsystems of the same economy. Two systems represented by first order differential equations, coupled together, will form a system that is capable of generating endogenous oscillations. We model such coupled systems to investigate international business cycle dynamics.

As customary in the physical sciences, we use a single over-dot to designate a first order time derivative and double over-dots to designate a second time derivative. A simple system that generate an oscillatory solution path is the familiar second order differential equation

$$
\ddot{y}+y=0,
$$

which could be converted into a two equation system of first order differential equations by introducing a second variable $x=\dot{y}$.

$$
\begin{aligned}
& \dot{x}=-y, \\
& \dot{y}=x .
\end{aligned}
$$

The growth rate of the variable $y$ is governed by $x$, and while the growth rate of $x$ is governed by negative $y$. As a result, the system can represent interactions between two opposing forces. In that manner, we identify models of opposing forces to generate oscillations. The above system, for instance, has the general solution

$$
\begin{aligned}
& x_{t}=x_{o} \cos t-y_{o} \sin t, \\
& y_{t}=x_{o} \sin t+y_{o} \cos t,
\end{aligned}
$$

where $y_{o}$ and $x_{o}$ are values of $x$ and $y$ at time zero. Without any interaction, both systems would stay at the steady state, which is the initial values $\left(x_{o}, y_{o}\right)$. Unless $x_{o}=y_{o}=0$ the "cost" of interaction is fluctuations. However, the gains from synchronization appear, when stochastic systems are considered. We show that the gains will be in the form of reduction in variances and reduced amplitudes of the processes converging to the steady state. 


\subsection{A Stochastic model of endogenous cycles}

One of the earliest business cycle models was Samuelson's (1939) well-known multiplieraccelerator model, named after the two parameters involved. The model was a second order autoregressive output equation. The model represents consumption as a function of last period's total expenditure, and investment as a function of the present and past period's total expenditure. With constant government expenditure, $\bar{G}$, the system yields the desired $\mathrm{AR}(2)$ process for total income, $Y_{t}$ :

$$
Y_{t+2}-\gamma(1+\alpha) Y_{t+1}+\alpha \gamma Y_{t}=\bar{G}
$$

We use the overbar notation to designate steady state value. Depending on the value of $(\gamma, \alpha)$, the process has the ability to generate a variety of time paths, including perpetual oscillations.

Another "base model" of an AR(2) process of output is Romer (2001, pages 174-186), which does not have the capacity to generate endogenous oscillations. Romer's model is a macroeconomic model requiring a stream of exogenous shocks to produce economic fluctuations. Similar models can be found in Prescott (1986), Christiano and Eichenbaum (1992), Baxter and King (1993), and Campbell (1994).

We now generate a model which, similarly to Samuelson's model, is capable of turning shocks into oscillations, without the need for a continuous sequence of shocks. As motivated by the previous section, government and consumer-investors will act as opposing forces on the economy leading to oscillatory fluctuations.

In the following closed economy income equation, $C_{t}$ is consumption expenditure, $I_{t}$ is investment expenditure, and $G_{t}$ is government expenditure during time period $t$ :

$$
Y_{t}=C_{t}+I_{t}+G_{t}
$$

The steady state values satisfy,

$$
\bar{Y}=\bar{C}+\bar{I}+\bar{G},
$$

so that

$$
Y_{t}-\bar{Y}=C_{t}-\bar{C}+I_{t}-\bar{I}+G_{t}-\bar{G} .
$$


Consumption and investment are related with the previous year's expenditure through the marginal propensities:

$$
Y_{t}-\bar{Y}=(c+i)\left(Y_{t-1}-\bar{Y}\right)+G_{t}-\bar{G}
$$

Subtracting $Y_{t-1}-\bar{Y}$ from both sides yields

$$
\triangle Y_{t}=(c+i-1)\left(Y_{t-1}-\bar{Y}\right)+G_{t}-\bar{G}
$$

In continuous time, with the addition of a Gaussian noise term, equation (9) becomes

$$
d Y_{t}=\left[-\delta_{2}\left(Y_{t-1}-\bar{Y}\right)+G_{t}-\bar{G}\right] d t+\sigma d U_{t}
$$

where $\delta_{2}$ is $1-c-i$, and $U_{t}$ is a Wiener process, with properties $E\left[U_{t}\right]=0$ and $\operatorname{Var}\left(U_{t}\right)=t$, where $U_{0}=0$. In classical mechanics, this equation is called a mean reverting OrschelinUhlenbeck process, where the variable $Y$ returns to its steady-state value $\bar{Y}$ if $G$ is constant. The other equation of the system is the government's control equation,

$$
d G_{t}=\left[-\delta_{1}\left(G_{t}-\bar{G}\right)-\omega^{2}\left(Y_{t}-\bar{Y}\right)\right] d t
$$

This equation is also mean-reverting. The government increases its spending, when it is at steady state $\bar{G}$, and when output is below the steady state value $\bar{Y}$. Conversely, when output is above its steady state, government cools off the economy by reducing its spending. When output is at steady state and $G$ is not, $G$ reverts to steady state following a smooth path at a rate of $\delta_{1}$. For the sake of simplicity, the control equation is assumed to be noise-free. The government is assumed to have perfect information on the output series, whereas consumers and investors observe a noisy process

$$
\left(Z_{t}-\bar{Z}\right) d t=\left(Y_{t}-\bar{Y}\right) d t+\gamma d V_{t}
$$

where $V$ is again a Wiener process similar to and independent of $U$. Combining these three equations together, we obtain the system of equations

$$
\begin{aligned}
d G_{t} & =-\omega^{2}\left(Y_{t}-\bar{Y}\right) d t-\delta_{1}\left(G_{t}-\bar{G}\right) d t \\
d Y_{t} & =\left[-\delta_{2}\left(Z_{t}-\bar{Z}\right)+G_{t}-\bar{G}\right] d t+\sigma d U_{t} \\
\left(Z_{t}-\bar{Z}\right) d t & =\left(Y_{t}-\bar{Y}\right) d t+\gamma d V_{t}
\end{aligned}
$$


where the first two equations are the system equations, and the last equation is the observation equation. For the sake of simplicity, we adopted an approach to represent the observation equation that differs from the mainstream filtering theory representation. Substituting the observation equation in the second system equation, we obtain the system in reduced form.

Definition 2.1.1. The system in reduced form is

$$
\begin{aligned}
d G_{t} & =-\omega^{2}\left(Y_{t}-\bar{Y}\right) d t-\delta_{1}\left(G_{t}-\bar{G}\right) d t \\
d Y_{t} & =\left[-\delta_{2}\left(Y_{t}-\bar{Y}\right)+G_{t}-\bar{G}\right] d t+\sigma d U_{t}-\delta_{2} \gamma d V_{t}
\end{aligned}
$$

We may represent the above system in vector form as

$$
d X_{t}=A X_{t} d t+\Sigma d W_{t}
$$

where

$$
\begin{aligned}
X_{t} & =\left(G_{t}-\bar{G}, Y_{t}-\bar{Y}\right)^{T}, \\
W_{t} & =\left(U_{t}, V_{t}\right)^{T}, \\
A & =\left[\begin{array}{cc}
-\delta_{1} & -\omega^{2} \\
1 & -\delta_{2}
\end{array}\right], \\
\Sigma & =\left[\begin{array}{cc}
0 & 0 \\
\sigma & -\delta_{2} \gamma
\end{array}\right] .
\end{aligned}
$$

The solution is given by

$$
X_{t} \equiv e^{t A}\left[X_{0}+\Sigma \int_{0}^{t} e^{-s A} d W_{s}\right]
$$

where $e^{t A}=\sum_{n=0}^{\infty} \frac{t^{n}}{n !} A^{n}$ is a particular matrix having the same dimension as $A$.

If we assume that the output and government spending return to their steady state values, with the same rate when other variables are already at their steady state values, so that $\delta_{1}=\delta_{2} \equiv \delta$, then the matrix $e^{t A}$ could be factored out as follows:

$$
\begin{aligned}
e^{t A} & =e^{-\delta t} e^{t C}, \\
e^{t C} & =\left[\begin{array}{cc}
\cos \omega t & -\omega \sin \omega t \\
\frac{1}{\omega} \sin \omega t & \cos \omega t
\end{array}\right],
\end{aligned}
$$


so that there is a convenient open form solution for $X$ :

$$
X_{t} \equiv e^{-\delta t} e^{t C} X_{0}+\Sigma \int_{0}^{t} e^{-\delta(t-s)} e^{(t-s) C} d W_{s}
$$

For our model, the expected value of the process $X_{t}$ could be defined as a deterministic process by itself, so that

$$
\begin{aligned}
\dot{M}_{t} & =A M_{t}, \\
M_{t} & \equiv E\left[X_{t}\right]
\end{aligned}
$$

\section{Proposition 2.1.1.}

The solution for $M_{t}$ given the case $\delta_{1}=\delta_{2}=\delta$ is

$$
\begin{aligned}
E\left[G_{t}\right] & =e^{-\delta t}\left[\left(G_{0}-\bar{G}\right) \cos \omega t-\left(Y_{0}-\bar{Y}\right) \omega \sin \omega t\right] \\
E\left[Y_{t}\right] & =e^{-\delta t}\left[\left(G_{0}-\bar{G}\right) \frac{1}{\omega} \sin \omega t+\left(Y_{0}-\bar{Y}\right) \cos \omega t\right] .
\end{aligned}
$$

For the more general case $\delta_{1} \neq \delta_{2}$, the condition for the mean process $M$ to be oscillatory is $\left(\delta_{1}-\delta_{2}\right)^{2}<4 \omega^{2}$, which clearly holds for the particular case $\delta_{1}=\delta_{2}$. In the general case, oscillations could still be possible, if the government responds to the disturbances in production, $U_{t}$, more severely by keeping the response coefficient $\omega^{2}$ high.

For convergence of $M_{t}$, the condition is $\delta_{1}+\delta_{2}>0$, which is assumed for this particular model. Under this condition, the oscillations generated by a larger value of $U_{t}$ will die out, and the economy will return to smaller fluctuations until the next shock to the system. In general, $\omega^{2}$ represents the responsiveness of the government to the random walk nature of the output shocks, and $\delta_{1}$ represents the speed with which the government gets back to a normal level of spending. If for some reason, the government spending change, which start as a response to output deviation, becomes persistent and generates further changes in the same direction, then $\delta_{1}$ turns negative, and perpetual oscillations becomes a possibility. One of the reasons for staggering change in $G$ in positive direction could be growth concerns. If the government has growth concerns, then the government may adopt a negative value for $\delta_{1}$. As a result, government will keep increasing spending in the steady state of the economy to promote economic growth. In this case, if the condition $\delta_{1}+\delta_{2}=0$ is satisfied, with the additional condition $\delta_{2}^{2}=\delta_{1}^{2} \equiv \delta^{2}<\omega^{2}$, there will be no damping to the system, and output and government spending will oscillate indefinitely, even without any disturbance to 
the system. On the other hand, when government further decreases spending for political reasons after a corrective budget cut, $\delta_{1}<0$ will again hold.

The stability conditions for the actual noisy system are harder to determine. Generally speaking, the law of motion for the covariance matrix is

$$
\dot{V}_{t}=A V_{t}+V_{t} A^{T}+\Sigma \Sigma^{T}
$$

When the above covariance system is stable, the variances for the series will tend to steady state values as $t \rightarrow \infty$. For the case $\delta_{1}+\delta_{2}>0$, the covariance matrix steady state can be found by setting $\dot{V}_{t}=0$ to yield the following:

\section{Proposition 2.1.2.}

$$
\begin{aligned}
\overline{\operatorname{Var}}(G) & =\omega^{4} \frac{\sigma^{2}+\delta_{2}^{2} \gamma^{2}}{2\left(\delta_{1}+\delta_{2}\right)\left(\omega^{2}+\delta_{1} \delta_{2}\right)}, \\
\overline{\operatorname{Var}}(Y) & =\frac{\sigma^{2}+\delta_{2}^{2} \gamma^{2}}{2 \delta_{2}}\left[1-\frac{\omega^{2} \delta_{1}}{\left(\delta_{1}+\delta_{2}\right)\left(\omega^{2}+\delta_{1} \delta_{2}\right)}\right], \\
\overline{\operatorname{Cov}}(G, Y) & =-\omega^{2} \delta_{1} \frac{\sigma^{2}+\delta_{2}^{2} \gamma^{2}}{2\left(\delta_{1}+\delta_{2}\right)\left(\omega^{2}+\delta_{1} \delta_{2}\right)} .
\end{aligned}
$$

For the case $-\delta_{1}=\delta_{2} \equiv \delta$, the covariance matrix $V_{t}$ perpetually oscillates. With this model, stability conditions for the mean process $M_{t}$ and the covariance process $V_{t}$ are identical. Whenever $M_{t}$ fluctuates, $V_{t}$ fluctuates; whenever $M_{t}$ oscillates perpetually, $V_{t}$ oscillates perpetually.

The stochastic system under consideration here is non-diffusive; that is, the system noise term is not a function of the variables of the system. Therefore, it is generally not possible to identify a system which is strictly stable in the stochastic sense. However, if the expectedvalue system is stable, the stochastic system may also be stable under "small" observation and system noise.

The model distinguishes between the short run "reflex" action of the government, and the concerns of growth. When the government does not have long-term growth concerns but takes action for some other reason, the economy will eventually return to its steady state. If the multiplier effect is large, this return to steady state may take a long time. In contrast the long-term growth concerns of the government and the frictions in the political decisionmechanism could yield a variety of system dynamics. For instance, the system mean and variance will oscillate indefinitely if $-\delta_{1}=\delta_{2} \equiv \delta<\omega^{2}$. In general, if the multiplier effect in the economy is large, so that the return to steady state is slow, strong government action against deviations may generate further deviations and fluctuations. 


\subsection{Stochastic models of business cycles: two open economies}

Another application of a system of coupled subsystems is the analysis of economies with financial and trade links. In an attempt to avoid a complex model with many parameters, we assume only trade links in this section. We use two different modeling approaches: linear and nonlinear.

\subsubsection{Linear case}

The model is again one of the basic models of macroeconomics:

$$
\begin{aligned}
Y & =C(Y)+I(r, Y)+G+T\left(e P^{*} / P, Y, Y^{*}\right), \\
Y^{*} & =C^{*}\left(Y^{*}\right)+I^{*}\left(r^{*}, Y^{*}\right)+G^{*}-\frac{P}{e P^{*}} T\left(e P^{*} / P, Y, Y^{*}\right) .
\end{aligned}
$$

The above model is from Rødseth (2000, p.293), but our discussion and use will differ from his. The two countries are assumed to be their only trade partners. As a result, the trade balance $T(\cdot)$ is the same term for both countries, in home country's currency, and is converted into foreign country terms in the foreign output equation by the real exchange rate, $R \equiv e P^{*} / P$. Consumption, investment, and government spending are functions of domestic output. We again assume that there are constant marginal propensities to consume and invest, and government spending has a constant share in total expenditure. The propensities to consume and invest and the government's share in total expenditure sum up to $1-\delta$. Constant interest rates are assumed for simplification.

The trade balance is assumed to be linear in expenditure of both countries, so that

$$
\begin{aligned}
T & =-\lambda^{2}(Y-\bar{Y})-R \omega^{2}\left(Y^{*}-\bar{Y}^{*}\right) \\
T^{*} & =\omega^{2}\left(Y^{*}-\bar{Y}^{*}\right)+R^{-1} \lambda^{2}(Y-\bar{Y}), \\
R & \equiv e P^{*} / P .
\end{aligned}
$$

Note that the above trade balances satisfy $T+R T^{*}=0$. This representation is similar to the gravity approach of trade volume (Feenstra, 2002), when the output figures are in logarithms. But here the model is for the trade balance rather then the trade volume of the gravity model.

Each country is identified with one side of the trade. Home is affiliated with imports, since an increase in expenditure above the home steady state level yields an increase in imports, and the trade balance turns negative. Likewise, an increase in foreign output above steady 
state level will increase imports of home and again yield a higher negative trade balance. Foreign, on the other hand, is identified with exports. An increase in home expenditure will increase foreign exports, and a positive output shock in foreign will have the same affect.

Tables 1 and 2 of the appendix display cross-correlations of output and bilateral trade for OECD countries. The signs of the coefficients for the trade equation above could be justified for many pairs of countries. For instance, the signs are valid for country pairs US-Canada, US-Denmark, and US-France for the period 1985Q1-2003Q4.

The output equations then become

$$
\begin{aligned}
d Y_{t} & =\left[\left(-\lambda^{2}-\delta\right)\left(Y_{t}-\bar{Y}\right)-\omega^{2} R\left(Y_{t}^{*}-\bar{Y}^{*}\right)\right] d t \\
d Y_{t}^{*} & =\left[\left(\omega^{2}-\delta^{*}\right)\left(Y_{t}^{*}-\bar{Y}^{*}\right)+\lambda^{2} R^{-1}\left(Y_{t}-\bar{Y}\right)\right] d t
\end{aligned}
$$

The propensities to trade are constant for both countries. If we further assume growth rates with local and global shocks, (29) will become as follows.

Definition 2.2.1.1. The output series of two open economies are defined by the system

$$
\begin{aligned}
d Y_{t} & =\left[\left(-\lambda^{2}-\delta\right)\left(Y_{t}-\bar{Y}\right)-\omega^{2} R\left(Y_{t}^{*}-\bar{Y}^{*}\right)\right] d t+\sigma d U_{t}+\nu d B_{t}, \\
d Y_{t}^{*} & =\left[\left(\omega^{2}-\delta^{*}\right)\left(Y_{t}^{*}-\bar{Y}^{*}\right)+\lambda^{2} R^{-1}\left(Y_{t}-\bar{Y}\right)\right] d t+\sigma^{*} d U_{t}^{*}+\nu^{*} d B_{t},
\end{aligned}
$$

where $\sigma\left(\sigma^{*}\right)$ is the standard deviation of the domestic shock for the home (or foreign) country, and $\nu\left(\nu^{*}\right)$ is the standard deviation of the world shock, as observed by the home (or foreign) country. We define $U, U^{*}$, and $B$ to be independent Wiener processes.

In matrix form, (30) becomes

$$
d X_{t}=A X_{t} d t+\Sigma d W_{t}
$$

where

$$
\begin{aligned}
A & =\left[\begin{array}{cc}
-\lambda^{2}-\delta & -\omega^{2} R \\
\lambda^{2} R^{-1} & \omega^{2}-\delta^{*}
\end{array}\right], \\
\Sigma & =\left[\begin{array}{ccc}
\nu & \sigma & 0 \\
\nu^{*} & 0 & \sigma^{*}
\end{array}\right], \\
X_{t} & =\left(Y_{t}-\bar{Y}, Y_{t}^{*}-\bar{Y}^{*}\right)^{T}, \\
W_{t} & =\left(B_{t}, U_{t}, U_{t}^{*}\right)^{T},
\end{aligned}
$$


and $X_{0}=\left(Y_{0}-\bar{Y}, Y_{0}^{*}-\bar{Y}^{*}\right)^{T}$ is the vector of initial values.

All the shocks in the system represent both the cumulative shocks to the output growth rate and to trade. The open form exact solution for this case is fairly complex, except under the very restrictive condition $-\lambda^{2}-\delta=\omega^{2}-\delta^{*}$. However, the existence of stable oscillatory solutions can be investigated without the open form solution. These conditions are given by the following proposition.

\section{Proposition 2.2.1.1.}

(i) $M \equiv E[X]$ is oscillatory, if $\left(\delta-\delta^{*}+\lambda^{2}+\omega^{2}\right)^{2}<4 \lambda^{2} \omega^{2}$, and

(ii) oscillations converge to the steady state values $\left(\bar{Y}, \bar{Y}^{*}\right)$, if $\delta+\delta^{*}>\omega^{2}-\lambda^{2}$.

The steady state variances of $\left(Y, Y^{*}\right)$ will satisfy

$$
\frac{\overline{\operatorname{Var}}(Y)}{\omega^{2}}=R^{2} \frac{\overline{\operatorname{Var}}\left(Y^{*}\right)}{\lambda^{2}} .
$$

Specifically, the variances, covariance, and the correlation coefficient are

$$
\begin{aligned}
\overline{\operatorname{Var}}(Y) & =\frac{\sigma^{2}+\nu^{2}+\frac{\omega^{2}}{\lambda^{2}} R^{2}\left(\sigma^{* 2}+\nu^{* 2}\right)}{2 K}, \\
\overline{\operatorname{Var}}\left(Y^{*}\right) & =\frac{\frac{\lambda^{2}}{\omega^{2}} R^{-2}\left(\sigma^{2}+\nu^{2}\right)+\sigma^{* 2}+\nu^{* 2}}{2 K}, \\
\overline{\operatorname{Cov}}\left(Y, Y^{*}\right) & =\frac{\nu \nu^{*}}{K}, \\
\overline{\operatorname{Corr}}\left(Y, Y^{*}\right) & =\frac{2 \nu \nu^{*}}{R^{-1} \frac{\lambda}{\omega}\left(\sigma^{2}+\nu^{2}\right)+R \frac{\omega}{\lambda}\left(\sigma^{* 2}+\nu^{* 2}\right)}, \\
K & =\lambda^{2}-\omega^{2}+\delta+\delta^{*} .
\end{aligned}
$$

The gains from trade are certain, when we compare the above results with the no trade case, $\lambda^{2}=\omega^{2}=0$ :

$$
\begin{aligned}
\widetilde{\operatorname{Var}}\left(Y_{t}\right) & \rightarrow \frac{\sigma^{2}+\nu^{2}}{2 \delta}, \quad \text { as } t \rightarrow \infty, \\
\widetilde{\operatorname{Var}} Y_{t}^{*} & \rightarrow \frac{\sigma^{* 2}+\nu^{* 2}}{2 \delta^{*}}, \quad \text { as } t \rightarrow \infty, \\
\widetilde{\operatorname{Cov}}\left(Y_{t}, Y_{t}^{*}\right) & \rightarrow \frac{\nu \nu^{*}}{\delta+\delta^{*}}, \quad \text { as } t \rightarrow \infty, \\
\widetilde{\operatorname{Corr}}\left(Y_{t}, Y_{t}^{*}\right) & \rightarrow \frac{2 \nu \nu^{*}}{\delta+\delta^{*}} \times \sqrt{\frac{\delta \delta^{*}}{\left(\sigma^{2}+\nu^{2}\right)\left(\sigma^{* 2}+\nu^{* 2}\right)}}, \quad \text { as } t \rightarrow \infty .
\end{aligned}
$$


The gains from trade in that respect could be smaller variances and covariance. The trade connecting two economies could stabilize both sides, thereby generating systems that are easier to predict.

Proposition 2.2.1.2. Both home and foreign will face a reduction in variances, if $\lambda^{2}-\omega^{2}>\max \left\{0, \quad \frac{\lambda^{2}}{\omega^{2}} R^{-2} \frac{\sigma^{* 2}+\nu^{* 2}}{\sigma^{2}+\nu^{2}} \delta^{*}-\delta\right\}$ without any restrictions imposed on $\delta$ or $\delta^{*}$.

Attention should be paid to the relationship between the steady-state variances, as expressed by (33). The overall gain from trade is the smaller variances. However, the variances in the limit could be even lower for home with lower $R$, and for foreign with higher $R$.

If we investigate the amplitudes as expressed by the variation of output series from the steady state at peak $(r)$ to that at $(-r)$ :

$$
\begin{aligned}
r_{t}^{2} & =e^{-\alpha t}\left[\left(Y_{o}-\bar{Y}\right)^{2}+R^{2} \frac{\omega^{2}}{\lambda^{2}}\left(Y_{o}^{*}-\bar{Y}^{*}\right)^{2}\right], \\
r_{t}^{* 2} & =e^{-\alpha t}\left[R^{-2} \frac{\lambda^{2}}{\omega^{2}}\left(Y_{o}-\bar{Y}\right)^{2}+\left(Y_{o}^{*}-\bar{Y}^{*}\right)^{2}\right] .
\end{aligned}
$$

We set $-\alpha=-\lambda^{2}-\delta=\omega^{2}-\delta^{*}$ without loss of generality. It is also apparent that home is worse off and foreign is better off with higher $R$.

We will conclude this section by observing that trade links could generate interesting dynamics that cannot be observed in linear first order-single equation systems. For example, in a multi-equation system, economic fluctuations could be generated and regulated through trade links and exchange rate regimes.

\subsubsection{Nonlinear case}

The constant-propensities-to-import assumption for the linear model was restrictive and did not allow us to observe the system dynamics, when the trade links are subject to change. Table 2 of the appendix illustrates the changing relationship between output and trade among the USA and other OECD countries. The nonlinear model constructed in this section will assume that trade links in the linear model may change direction. That is, a country prone to import rather than export may turn into a competitive exporter as a result of the economic dynamics inside or outside the country.

Here, it will be assumed that the trade balance is a function of the output of the other country, with a normally distributed coefficient. The model is similar to (30), but the trade component related to the other country's output has a random coefficient, so that

$$
d Y_{t}=-\gamma\left(Y_{t}-\bar{Y}\right)-R\left(Y_{t}^{*}-\bar{Y}^{*}\right) \sigma d B_{t},
$$




$$
d Y_{t}^{*}=-\gamma^{*}\left(Y_{t}^{*}-\bar{Y}^{*}\right)+R^{-1}\left(Y_{t}-\bar{Y}\right) \sigma d B_{t}
$$

For the home country, the coefficient of own output in (30) is now consolidated to one parameter $\gamma$, and the coefficient of the other country's output is normally distributed with zero mean and variance $\sigma^{2}$. The arrangements are similar for foreign. Note that here $\sigma$ represents the magnitude of noise, as well as its effect on both economies as a coefficient of interaction.

The solution for the system above is called "Brownian motion on an ellipse," with center $\left(\bar{Y}, \bar{Y}^{*}\right)$ and radii $\left(X_{0}, R^{-1} X_{0}\right)$, where $X_{0}=Y_{0}-\bar{Y}$ is home's output at time zero. The solution could be represented as

$$
\begin{aligned}
Y_{t} & =\bar{Y}+X_{0} \exp \left[\left(-\gamma+\frac{\sigma^{2}}{2}\right) t\right] \cos \sigma B_{t} \\
Y_{t}^{*} & =\bar{Y}^{*}+R^{-1} X_{0} \exp \left[\left(-\gamma^{*}+\frac{\sigma^{2}}{2}\right) t\right] \sin \sigma B_{t}
\end{aligned}
$$

Because of the restrictive nature of the model, the phase difference between the series should always be $\pi / 2$. Therefore, the economies are fully synchronized with our definition of synchronization. If we investigate the expected values of these series, one can observe the following limits:

\section{Proposition 2.2.2.1.}

$$
\begin{aligned}
& \gamma>0 \Rightarrow E[Y] \rightarrow \bar{Y} \quad \text { and } \quad E\left[Y^{*}\right] \rightarrow \bar{Y}^{*}, \quad \text { as } t \rightarrow \infty \\
& \gamma=0 \Rightarrow E[Y] \rightarrow Y_{0} \quad \text { and } \quad E\left[Y^{*}\right] \rightarrow \bar{Y}^{*}, \quad \text { as } t \rightarrow \infty \\
& \gamma<0 \Rightarrow E[Y] \rightarrow \infty \quad \text { and } \quad E\left[Y^{*}\right] \rightarrow \infty, \quad \text { as } t \rightarrow \infty
\end{aligned}
$$

The expected value series behave similarly to the case with no trade: for nonnegative $\gamma$, both series are converging. The difference made by trade is apparent for the variance series:

Proposition 2.2.2.2.

$$
\begin{aligned}
& \gamma>\frac{\sigma^{2}}{2} \Rightarrow \operatorname{Var}(Y) \rightarrow 0 \quad \text { and } \quad \operatorname{Var}\left(Y^{*}\right) \rightarrow 0, \quad \text { as } t \rightarrow \infty, \\
& \gamma=\frac{\sigma^{2}}{2} \Rightarrow \operatorname{Var}(Y) \rightarrow \frac{X_{0}^{2}}{2} \quad \text { and } \quad \operatorname{Var}\left(Y^{*}\right) \rightarrow \frac{R^{-2} X_{0}^{2}}{2}, \quad \text { as } t \rightarrow \infty, \\
& \gamma<\frac{\sigma^{2}}{2} \Rightarrow \operatorname{Var}(Y) \rightarrow \infty \quad \text { and } \operatorname{Var}\left(Y^{*}\right) \rightarrow \infty, \quad \text { as } t \rightarrow \infty .
\end{aligned}
$$


With small variance of the random trade link, the series will converge. However, if the variance of the random coefficient is high, then both variance series will be explosive. A stationary or even deterministic series will result, if noise in the trade coefficient is small enough. However, for high noises variance, the variance of both output series will be explosive.

In the nonlinear model, reducing trade for the sake of a stationary variance series is necessary. Since $\sigma$ is also directly proportional to trade balance, both countries will have an incentive to reduce trade for a non-explosive variance series. The result will be the Pareto-inefficient solution of no trade.

\subsubsection{Partial synchronization}

The stochastic model above represents a fully synchronized pair of economies, benefiting from trade through volatility reduction. This section is devoted to an alternative approach, in which the economies may not be phase-locked.

In this context, we need to use complex variables.

Definition 2.2.3.1. The output in complex format is the variable

$$
z_{j}(t)=\left(Y_{j}(t)-\bar{Y}_{j}\right)+i X_{j}(t)
$$

where $X_{j}$ is the imaginary part of $z_{j}$ and $i^{2} \equiv-1$.

Here, it is assumed that the output follows the process $Y_{j}(t)-\bar{Y}_{j}=r(t) \cos \phi(t)$ and $X_{j}(t)=r(t) \sin \phi(t)$ is the corresponding imaginary process with amplitude $r(t)$ and phase $\phi(t)$. The model to be employed is a simple equation in complex variables that is capable of generating a stable limit cycle.

Definition 2.2.3.2. The output of a closed economy is given by the deterministic process $\dot{z}=\left(q^{2}-|z|^{2}+i \omega\right) z$, where the absolute value notation means amplitude of the complex variable.

The above equation has a limit cycle of amplitude $q$ and frequency $\omega$ and could be separated into amplitude and phase equations such that

$$
\begin{aligned}
\dot{r} & =\left(q^{2}-r^{2}\right) r \\
\dot{\phi} & =\omega,
\end{aligned}
$$

where the time scripts are dropped for the sake of simplicity. 
The amplitude equation has stable equilibrium at $r=q$ and an unstable equilibrium at $r=0$. In the next section, the discussion will be concentrated on how to make the zero state stable through synchronization. In this section, we find that the amplitude will eventually revert to its steady state value and stay mostly intact under small noise in the system. Unlike $r$, the phase $\phi$ does not have a value to which to converge. The "speed of revolution" could be disturbed by noise and stay at the new value forever. In other words, under additive noise, $\phi$ is a random walk process. This section is concentrated on regulating phase through links with other economies.

We now represent trade as follows. Exports are assumed to be a function of foreign expenditure, and imports are assumed to be a function of home expenditure. The trade balances then become

$$
\begin{array}{r}
T_{1}(t)=\rho_{1} R Y_{2}(t)-\delta_{1} Y_{1}(t), \\
T_{2}(t)=\rho_{2} R^{-1} Y_{1}(t)-\delta_{2} Y_{2}(t) .
\end{array}
$$

Definition 2.2.3.3. The output series of open economies in a two economy system is given by the deterministic processes

$$
\begin{aligned}
& \dot{z}_{1}=\left(q_{1}^{2}-\left|z_{1}\right|^{2}+i \omega_{1}\right) z_{1}+\rho_{1} R z_{2}-\delta_{1} z_{1}, \\
& \dot{z}_{2}=\left(q_{2}^{2}-\left|z_{2}\right|^{2}+i \omega_{2}\right) z_{2}+\rho_{2} R^{-1} z_{1}-\delta_{2} z_{2} .
\end{aligned}
$$

The equation for the law of motion of the output of an open economy could be decomposed into amplitude and phase components such that

$$
\begin{aligned}
& \dot{r}_{1}=\left(q_{1}^{2}-r_{1}^{2}-\delta_{1}\right) r_{1}+\rho_{1} R r_{2} \cos \left(\phi_{1}-\phi_{2}\right) \\
& \dot{\phi}_{1}=\omega_{1}-\rho_{1} R \frac{r_{2}}{r_{1}} \sin \left(\phi_{1}-\phi_{2}\right) .
\end{aligned}
$$

The equations are similar for the foreign economy with variables that are denoted by subscript 2. The system of noisy equations for phases $\left(\phi_{1}, \phi_{2}\right)$ then become

$$
\begin{aligned}
& \dot{\phi}_{1}=\omega_{1}-\rho_{1} R \frac{r_{2}}{r_{1}} \sin \left(\phi_{1}-\phi_{2}\right)+\eta_{1}, \\
& \dot{\phi}_{2}=\omega_{2}+\rho_{2} R^{-1} \frac{r_{1}}{r_{2}} \sin \left(\phi_{1}-\phi_{2}\right)+\eta_{2},
\end{aligned}
$$

where $\eta_{j} \sim$ i.i.d. $\left(0, \sigma_{j}^{2}\right)$. 
Proposition 2.2.3.1. The noise of the coupled system above is lower than the noise of separate closed economies, when $\frac{\sigma_{1}^{2}}{\sigma_{2}^{2}}>R^{2}\left(1-R^{2}\right)$ and when the following condition also is satisfied:

$$
\begin{aligned}
& {\left[1+2 a+\left(1-R^{2}\right) a^{2}\right]^{-1}<R^{2} \frac{\sigma_{2}^{2}}{\sigma_{1}^{2}}<1+2 a^{-1}+\left(1-R^{-2}\right) a^{-2}, \quad \text { if } R \leq 1} \\
& {\left[1+2 a^{-1}+\left(1-R^{-2}\right) a^{-2}\right]^{-1}<R^{2} \frac{\sigma_{2}^{2}}{\sigma_{1}^{2}}<1+2 a+\left(1-R^{2}\right) a^{2}, \quad \text { if } R>1,}
\end{aligned}
$$

and $a \equiv \frac{\rho_{1}}{\rho_{2}} \frac{q_{2}^{2}}{q_{1}^{2}} R^{2}$, with the economies are in or close to phase-locking state.

\section{Proof.}

The proof closely follows Malakhov (1968) as translated in Pikovsky et al. (2001.) First define $\psi=\phi_{1}-\phi_{2}, \epsilon_{1}=\rho_{1} R \frac{r_{2}}{r_{1}}, \epsilon_{2}=\rho_{2} R^{-1} \frac{r_{1}}{r_{2}}, \theta=\epsilon_{2} \phi_{1}+\epsilon_{1} \phi_{2}, \nu=\omega_{1}-\omega_{2}$. Then

$$
\begin{aligned}
\dot{\psi} & =\nu-\left(\epsilon_{1}+\epsilon_{2}\right) \sin \psi+\eta_{1}-\eta_{2}, \\
\dot{\theta} & =\epsilon_{2} \omega_{1}+\epsilon_{1} \omega_{2}+\epsilon_{2} \eta_{1}+\epsilon_{1} \eta_{2}, \\
\operatorname{Var}(\dot{\theta}) & =\epsilon_{2}^{2} \sigma_{1}^{2}+\epsilon_{1}^{2} \sigma_{2}^{2} .
\end{aligned}
$$

Write the phases in the form $\phi_{1}=\frac{\epsilon_{1} \psi+\theta}{\epsilon_{1}+\epsilon_{2}}$ and $\phi_{2}=\frac{-\epsilon_{2} \psi+\theta}{\epsilon_{1}+\epsilon_{2}}$. When the economies are phase locked, their phase difference is constant, so that $\dot{\psi}=0$. We find

$$
\operatorname{Var}\left(\dot{\phi}_{1}\right)=\frac{\epsilon_{2}^{2} \sigma_{1}^{2} R^{-2}+\epsilon_{1}^{2} \sigma_{2}^{2} R^{2}}{\left(\epsilon_{1}+\epsilon_{2}\right)^{2}}=\operatorname{Var}\left(\dot{\phi}_{2}\right)
$$

Note that the variances are minimum, when $R=1$. For the closed economies, $\widetilde{\operatorname{Var}}\left(\dot{\phi}_{j}\right)$ is $\sigma_{j}^{2}, j=1,2$. It is easy to verify that

$$
\frac{R^{-2} \epsilon_{2}^{2} \sigma_{1}^{2}+R^{2} \epsilon_{1}^{2} \sigma_{2}^{2}}{\left(\epsilon_{1}+\epsilon_{2}\right)^{2}}<\sigma_{j}^{2}, \quad j=1,2,
$$

when the proposition is satisfied. For practical purposes, note that $q_{j}, j=1,2$, which are the steady state values of $r_{j}, j=1,2$, could be substituted for $r_{j}, j=1,2$. Notice that without the condition $\dot{\psi}=0$, equation (47) would yield higher variances for both economies. Both economies benefit from phase synchronization in this situation. 
Attention should be paid to the regulating feature of the trade link in the phase equations. In (46), since the phase difference is always within the interval $[-\pi / 2, \pi / 2]$, the sine function is monotonically increasing, and regulates the phase of one economy while using the other as a milestone. Although the other economy might be a noisy milestone, it is better than none, as is the case of the closed economies. The coupling introduces a mechanism for the phase to "return" to a certain level, although this may be impossible for the closed economy case. The linearization of the phase equations around zero phase-difference also can produce a stable solution.

The ideas presented in this section could be generalized to a system of many countries by treating economy number 2 as the "rest of the World" and carrying out the analysis exactly as above. The World then should be viewed as a collection of economies close to phase-locking with each other, so that we may talk about a World business cycle with given natural frequency and amplitude.

\subsubsection{Concluding remarks}

We have investigated the dynamics of economies from a stochastic dynamic point of view. The stability conditions identified are in parallel with rationality and the economic literature. Relative to variance of output fluctuations, there are benefits from a balanced trade. In a more general sense, the lower that the output fluctuations of foreign are reflected at home, the milder the fluctuations at home would be.

Further analysis is needed for the case in which a group of economies interact in a "World Economy." Then, the analysis is much more complex, since we are in the domain of systems of dimension greater than two. The valuable aid from the Poincare-Bendixton theorem will be lost, and other techniques need to be employed to identify steady states of the system. This analysis is done in the next section.

\section{Canonical Model for International Synchronization: The Multicountry Case}

In this section, we propose a canonical model for business cycle synchronization through trade links. It is assumed that all accounting are done in terms of one numeraire currency, so exchange rate terms could be omitted. The "exports" of each country are a function of total world expenditure, and imports are a function of domestic expenditure. In particular, we have

$$
T_{j}(t)=\rho_{j} \frac{1}{N} \sum_{k} Y_{k}(t)-\delta_{j} Y_{j}(t),
$$

where $N$ is the number of countries in the system under consideration.

Here, exports are assumed to be a function of average total expenditure in an attempt to 
keep coefficients $\rho$ and $\delta$ in the same order of magnitude. This convention will also serve to switch to the asymptotic case, when the number of countries in the system gets large.

The economies are assumed to go through a stable limit cycle with a predetermined constant frequency and amplitude. Also, the steady state is an unstable equilibrium. Definitions 2.2.3.1 and 2.2.3.2 apply also for this section. Appending the trade links to the equation in Definition 2.2.3.2, we get

$$
\dot{z}_{j}=\left(q_{j}^{2}-\left|z_{j}\right|^{2}+i \omega_{j}\right) z_{j}+\rho_{j} \frac{1}{N} \sum_{k} z_{k}-\delta_{j} z_{j}
$$

Rearranging terms,

$$
\dot{z}_{j}=\left(q_{j}^{2}-\delta_{j}-\left|z_{j}\right|^{2}+i \omega_{j}\right) z_{j}+\rho_{j} \frac{1}{N} \sum_{k} z_{k}
$$

When linearized at the rest state $\left|z_{j}\right|=0, \forall j$, the equation becomes

$$
\dot{z}_{j}=\left(q_{j}^{2}-\delta_{j}+i \omega_{j}\right) z_{j}+\rho_{j} P(t)
$$

where $P(t)=\frac{1}{N} \sum_{k} z_{k}$ is the "World Business Cycle" defined in the Introduction.

So, an "economy" is identified by four parameters: $q_{j}$ for amplitude, $\omega_{j}$ for frequency, $\rho_{j}$ for foreign effect on trade balance, and $\delta_{j}$ for domestic effect on trade balance. The solution for the above equation then could be represented in terms of $P(t)$ as follows (Ermentrout, 1990):

$$
z_{j}=\exp \left[\left(q_{j}^{2}-\delta_{j}+i \omega_{j}\right) t\right] z_{j}(0)+\rho_{j} \int_{0}^{t} \exp \left[\left(q_{j}^{2}-\delta_{j}+i \omega_{j}\right)(t-s)\right] P(s) d s
$$

At this point, the requirement for rescaling the system is apparent. Equations for all economies should be rescaled to satisfy $q_{j}^{2}<\delta_{j}$ in which case the first term of the solution vanishes as $t \rightarrow \infty$.

After a series of approximations and manipulations, the following condition is derived for stability of the steady state, at which all fluctuations vanish.

Proposition 3.1. The rest state for (53) is stable, if

$$
E\left[q^{2}\right]-E[\delta]<\min \left\{0, \quad \sqrt[3]{\frac{E[\rho]}{1+E[\rho]}\left[\operatorname{Var}(\omega)-\operatorname{Var}\left(q^{2}\right)-\operatorname{Var}(\delta)\right]}\right\}
$$


Assuming $E[\rho]$ positive, only $E\left[q^{2}\right]<E[\delta]$ is required for amplitude death to be stable. We also are assuming that frequencies have high enough variance. However, when natural frequencies are more concentrated, mean amplitude would need to be smaller for the zero amplitude state to be stable.

Returning to (49), observe that when $\sum_{k} T_{k}(t)=0$ is satisfied, then $D=\sum_{k} \rho_{k}$ becomes an aggregate for $\delta_{j}$ 's, $Q=\frac{1}{N} \sum_{k} Y_{k}$ becomes an aggregate for $Y_{j}$ 's and Fisher's factor reversal test is satisfied: $D Q=\sum_{j} \delta_{j} Y_{j}$. Asymptotically, we find that $E[\rho]$ is closely related to $E[\delta]$. The economic interpretation is that, if the exports are reduced, the right hand side of $(54)$ will get close to zero. But in effect, the imports will be reduced too, and the left hand side of (54) will get closer to $E\left[q^{2}\right]$, which is assumed to be nonnegative. So, stabilization of the zero amplitude state is not possible by reducing the trade links.

\section{Conclusion}

This paper investigates the transmission mechanisms of noise among countries through trade links, and the effects of synchronization on the domestic business cycles. We identify conditions under which international economic links reduce aggregate volatility and noise emanating from the noise embedded within the individual economic systems.

From the dynamical systems approach, we find that there are two effects of external links: (1) regulating the cycles of the domestic economies, thereby reducing volatility and noise and (2) transmitting additional noise from outside the economies. We find under certain conditions that economies benefit from international links, regardless of the magnitude of external noise. We also find that exchange rate regimes play a role in the control of noise and volatility. Generally speaking, a higher real exchange rate for a mostly-importing home country may increase the noise and volatility in that country's business cycle. If such a country completely blocks trade in an attempt to reduce transmission of outside noise, the result will be the Pareto inferior state of no trade. Bilateral cooperation of countries on trade issues is shown to be preferable to unilateral action.

The final section derives conditions under which linkage among all economies of the world smooths out their business cycles. The result is to set the zero-amplitude state as the steady state. Then the "World economy" system may be free of fluctuations under small noise shocks. The conclusion depends upon testable hypotheses regarding model parameters. In contrast, we find that when the domestic economies have similar natural fluctuation frequencies, stronger links between economies generate stronger international business cycles, and decrease the chance for the no-fluctuation state to be stable. 


\section{References}

Adelman, I., and Adelman, F. (1959), "The Dynamic Properties of the Klein-Goldberger Model," Econometrica 27 (4), 596-625.

Barnett, W. A., Geweke, J., and Shell, K. (eds.) (1989), Economic Complexity: Chaos, Sunspots, Bubbles, and Nonlinearity, Proceedings of the Fourth International Symposium in Economic Theory and Econometrics, Cambrridge University Press, Cambridge.

Barnett, W. A., Kirman, A. P., and Salmon M. (eds.) (1996), Nonlinear Dynamics and Economics, Proceedings of the Tenth International Symposium in Economic Theory and Econometrics, Cambridge University Press, Cambridge.

Barnett, W. A., and Serletis, A. (2000), "Martingales, Nonlinearity, and Chaos," Journal of Economic Dynamics and Control, June, vol. 24, pp. 703-724.

Barnett W. A., and He, Y. (2002), "Stabilization Policy as Bifurcation Selection: Would Stabilization Policy Work if the Economy Really Were Unstable?," Macroeconomic Dynamics, vol 6, no. 5, November, pp. 713-747.

Barnett, W. A., Deissenberg, C., and Feichtinger, C. (eds.) (2004), Economic Complexity: Non-Linear Dynamics, Multi-Agents Economies, and Learning, Proceedings of the Fourteenth International Symposium in Economic Theory and Econometrics, Elsevier, Amsterdam.

Blanchard, O., and Simon, J. (2001), "The Long and Large Decline in U.S. Output Volatility," Brookings Papers on Economic Activity vol.1, pp. 135-164.

Bordo, M. D., and Helbling, T. (2003), "Have National Business Cycles Become More Synchronized?" NBER Working Paper 10130.

Day, R. H. (1982), "Irregular Growth Cycles," American Economic Review, 72, pp. 406414.

Day, R. H., and Shafer, W. (1985), "Keynesian Chaos," Journal of Macroeconomics, vol. 7, pp. 277-295.

Day, R. H., and Shafer, W. (1986), "Ergodic Fluctuations in Deterministic Economic Models," MRG Working Paper no. 8631 (University of Southern California, Los Angeles, California).

Ermentrout, G. B. (1990), "Oscillation death in populations of 'all to all' coupled nonlinear oscillators," Physica D, 41, 219-231. 
Feenstra, R. C. (2002), "Border Effects and the Gravity Equation: Consistent Methods for Estimation," Scottish journal of Political Economy, 49 (5), p. 491.

Grandmont, J.- M. (1985), "On Endogenous Competitive Business Cycles," Econometrica, 53, no. 5 .

Hakim, V., and Rappel, W.J. (1992), "Dynamics of the globally coupled complex GinzburgLandau equation," Phys. Rev. A, 46 (12).

IMF (2001), "Business Cycle Linkages among Major Economies" in World Economic Outlook, October 2001, Washington D.C.

Lorenz, H. W. (1993), Nonlinear dynamical economics and chaotic motion, 2nd ed., Springler-Verlag.

Malakhov, A. N. (1968), Fluctuations in Self-Oscillatory Systems, Nauka, Moscow (in Russian).

Maliar, L., and Maliar, S. (2004), "Endogenous growth and endogenous business cycles," Macroeconomic Dynamics, 8, pp. 559-581.

Matthews, P. C., and Strogatz, S.H. (1990), "Phase diagram for the collective behavior of limit-cycle oscillators," Phys. Rev. Lett., 65 (14).

Nakagawa, N., and Kuramoto, Y. (1993), "Collective chaos in a population of globally coupled oscillators," Prog. Theor. Phys., 89 (2).

Obstfeld, M., and Rogoff, K. (2002), "Global Implications of the Self-Oriented National Monetary Rules," The Quarterly Journal of Economics, May 2002, pp. 503-535.

Otto, G., Voss, G., and Willard, L. (2001), "Understanding OECD Output Correlations," Research Discussion Paper 2001-05, Sydney, Reserve Bank of Australia.

Pollock, D. S. G. (1999), A handbook of time-series analysis, signal processing and dynamics, Academic Press.

Pikovsky, A., Rosenblum, M., and Kurths, J. (2001), Synchronization, Cambridge University Press.

Rødseth, A. (2000), Open economy macroeconomics, Cambridge University Press, Cambridge.

Romer, D. (2001), Advanced macroeconomics, 2nd ed., McGraw Hill, New York.

Samuelson, Paul A. (1939), "Interactions between the multiplier analysis and the principle 
of acceleration," Review of Economic Statistics, pp. 75-78.

Selover, D. D., Roderick V. J., and Kroll J. (2003), "Industrial Sector Mode-Locking and Business Cycle Formation" Studies in Nonlinear Dynamics and Econometrics 7, Issue 3.

Stock, J. H., and Watson, M. W. (2003), "Has the Business Cycles Changed? Evidence and Explanations," Federal Reserve Bank of Kansas City Symposium, Jackson Hole, Wyoming, August 28-30.

Strogatz, S. H. (2000), "From Kuramoto to Crawford: exploring the onset of synchronization in populations of coupled oscillators," Physica D, issue 143, pp. 1-20.

Stutzer, M. (1980), "Chaotic Dynamics and Bifurcation in a Macro-model," Journal of Economic Dynamics and Control, vol. 2, pp. 253-276. 
Appendix : Tables

Table 1. Correlation of Country GDP Difference Series with Partner Trade Balance.

Data source: SourceOECD, the OECD's Online Library of Statistical Databases, Books and Periodicals.

\begin{tabular}{|c|c|c|c|c|c|c|c|c|c|}
\hline \multicolumn{10}{|c|}{ COUNTRY } \\
\hline & Australia & Austria & Be-Lux & Canada & Czech R. & Denmark & Finland & France & Germany \\
\hline Start year & 1988 & 1995 & 1988 & 1988 & 1993 & 1988 & 1988 & 1988 & 1988 \\
\hline Partner & & & & & & & & & \\
\hline Australia & 0.79 & 0.15 & 0.42 & 0.27 & 0.01 & -0.36 & -0.24 & 0.01 & 0.85 \\
\hline Austria & 0.68 & $\mathrm{~N} / \mathrm{A}$ & 0.37 & 0.46 & 0.46 & -0.14 & -0.26 & 0.23 & 0.63 \\
\hline Belgium-Lux. & -0.03 & -0.11 & 0.31 & -0.14 & -0.28 & 0.43 & -0.24 & 0.07 & 0.44 \\
\hline Canada & 0.25 & 0.27 & 0.21 & 0.52 & -0.54 & 0.07 & -0.58 & -0.29 & 0.34 \\
\hline Czech R. & -0.04 & 0.23 & 0.39 & 0.52 & -0.41 & 0 & -0.36 & 0.06 & 0.36 \\
\hline Denmark & 0.72 & -0.36 & 0.11 & 0.11 & 0.38 & $\mathrm{~N} / \mathrm{A}$ & 0.18 & -0.06 & 0.73 \\
\hline Finland & -0.05 & 0.48 & -0.18 & 0.42 & -0.29 & -0.38 & $\mathrm{~N} / \mathrm{A}$ & 0.02 & 0.26 \\
\hline France & 0.66 & 0.02 & -0.04 & 0.39 & -0.26 & 0.08 & -0.02 & 0.45 & 0.38 \\
\hline Germany & 0.72 & -0.15 & 0.46 & 0.62 & 0.61 & 0.22 & 0.02 & 0.73 & $\mathrm{~N} / \mathrm{A}$ \\
\hline Greece & 0.15 & 0.01 & 0.18 & -0.15 & 0.36 & -0.38 & -0.52 & -0.07 & 0.35 \\
\hline Hungary & 0.71 & -0.31 & -0.33 & 0.36 & -0.05 & -0.18 & -0.42 & 0.6 & -0.2 \\
\hline Iceland & 0.16 & -0.02 & -0.54 & 0.26 & 0.7 & -0.43 & -0.09 & -0.47 & -0.18 \\
\hline Ireland & 0.78 & 0.06 & -0.28 & 0.4 & -0.3 & -0.04 & 0.14 & 0.29 & -0.54 \\
\hline Italy & 0.71 & -0.34 & 0.09 & 0.61 & -0.24 & 0.51 & -0.2 & 0.1 & 0.29 \\
\hline Japan & 0.1 & 0.5 & -0.3 & 0.46 & -0.53 & -0.46 & 0.3 & 0.52 & 0.48 \\
\hline Korea & -0.32 & 0.31 & 0.14 & 0.5 & -0.47 & -0.14 & -0.12 & 0.2 & 0.32 \\
\hline Mexico & 0.7 & -0.28 & -0.12 & 0.66 & -0.45 & 0.32 & -0.26 & -0.06 & 0.54 \\
\hline Netherlands & 0 & -0.04 & 0.01 & 0.69 & 0.25 & 0.51 & 0.08 & 0.15 & 0.04 \\
\hline New Zealand & -0.66 & 0.29 & -0.14 & 0.5 & -0.07 & 0.15 & -0.54 & 0.18 & 0.36 \\
\hline Norway & -0.21 & 0.65 & -0.31 & 0.52 & -0.34 & 0.07 & -0.51 & 0.44 & -0.49 \\
\hline Poland & 0.08 & 0.19 & 0.12 & 0.3 & 0.35 & 0.21 & -0.34 & -0.28 & 0.64 \\
\hline Portugal & 0.76 & -0.35 & -0.09 & 0.39 & 0.67 & 0.11 & -0.48 & -0.02 & 0.02 \\
\hline Slovak R. & 0.58 & 0.53 & 0.16 & 0.5 & 0.19 & -0.09 & -0.14 & 0.55 & -0.25 \\
\hline Spain & 0.13 & -0.36 & 0.09 & 0.6 & 0.2 & -0.11 & -0.2 & -0.38 & 0.16 \\
\hline Sweden & 0.53 & 0.83 & -0.5 & 0.64 & 0.31 & 0.15 & 0.38 & -0.27 & 0.59 \\
\hline Switzerland & 0.73 & -0.48 & 0.13 & 0.56 & 0.43 & -0.47 & -0.04 & 0.24 & -0.55 \\
\hline Turkey & 0.11 & 0.1 & -0.08 & 0.35 & 0.13 & 0.35 & -0.48 & 0.31 & 0.56 \\
\hline United Kingdom & 0.03 & 0.02 & -0.04 & 0.54 & 0.11 & 0.01 & -0.59 & -0.26 & 0.61 \\
\hline United States & 0.27 & -0.04 & 0.03 & -0.6 & -0.35 & -0.23 & -0.23 & -0.36 & 0.64 \\
\hline
\end{tabular}


Table 1. Continued. Correlation of Country GDP Difference Series with Partner Trade Balance.

Data source: SourceOECD, the OECD's Online Library of Statistical Databases, Books and Periodicals.

\begin{tabular}{|c|c|c|c|c|c|c|c|c|c|c|}
\hline \multicolumn{11}{|c|}{ COUNTRY } \\
\hline & Greece & Hungary & Iceland & Ireland & Italy & Japan & Korea & Mexico & Netherlands & $\mathrm{NZ}$ \\
\hline Start year & 1988 & 1992 & 1988 & 1988 & 1988 & 1988 & 1994 & 1990 & 1988 & 1989 \\
\hline Partner country & & & & & & & & & & \\
\hline Australia & 0.18 & -0.19 & 0.43 & -0.93 & 0.15 & -0.07 & 0.71 & 0.24 & 0.42 & 0.25 \\
\hline Austria & 0.1 & -0.85 & 0.33 & -0.75 & 0.03 & -0.66 & 0.06 & 0.55 & -0.72 & 0.33 \\
\hline Belgium-Lux. & 0.59 & -0.57 & 0.65 & -0.74 & 0.38 & 0.6 & 0.56 & 0.12 & -0.6 & -0.1 \\
\hline Canada & 0.08 & 0.87 & -0.1 & 0.69 & 0.13 & 0.16 & -0.08 & -0.2 & -0.39 & -0.37 \\
\hline Czech Republic & 0.67 & 0.79 & 0.28 & -0.79 & -0.08 & 0.69 & 0.18 & 0.26 & -0.32 & 0.61 \\
\hline Denmark & 0.41 & 0.19 & 0.62 & 0.14 & 0 & -0.72 & 0.23 & -0.25 & -0.66 & 0.17 \\
\hline Finland & 0.36 & 0.64 & 0.21 & 0.25 & -0.3 & -0.33 & 0 & 0.53 & -0.71 & 0.34 \\
\hline France & 0.47 & -0.22 & 0.54 & -0.74 & 0.03 & 0.49 & 0.62 & 0.21 & -0.75 & 0.41 \\
\hline Germany & 0.27 & -0.83 & 0.02 & -0.76 & 0.07 & -0.27 & 0.49 & 0.47 & -0.64 & 0.52 \\
\hline Greece & $\mathrm{N} / \mathrm{A}$ & -0.37 & 0.34 & -0.69 & 0.09 & 0.29 & -0.19 & -0.05 & -0.31 & 0.42 \\
\hline Hungary & 0.29 & $\mathrm{~N} / \mathrm{A}$ & 0.29 & 0.66 & 0.23 & 0.8 & -0.14 & -0.54 & 0.83 & 0.58 \\
\hline Iceland & -0.52 & -0.55 & $\mathrm{~N} / \mathrm{A}$ & -0.89 & 0.24 & 0.12 & 0.91 & -0.18 & 0.75 & 0.56 \\
\hline Ireland & 0.57 & -0.26 & 0.37 & 0.82 & -0.22 & -0.56 & 0.1 & 0.04 & 0.69 & 0.46 \\
\hline Italy & 0.57 & 0.9 & 0.36 & -0.95 & $\mathrm{~N} / \mathrm{A}$ & 0.31 & 0.44 & 0.48 & -0.81 & 0.31 \\
\hline Japan & -0.31 & 0.81 & 0.5 & -0.32 & -0.35 & $\mathrm{~N} / \mathrm{A}$ & 0.83 & 0.22 & 0.75 & 0.11 \\
\hline Korea & 0.56 & 0.85 & 0.14 & 0.55 & -0.25 & 0.16 & $\mathrm{~N} / \mathrm{A}$ & 0.6 & 0.8 & -0.27 \\
\hline Mexico & -0.1 & 0.55 & 0.34 & -0.5 & 0.37 & 0.79 & -0.09 & 0.15 & 0.67 & -0.13 \\
\hline Netherlands & 0.5 & -0.73 & -0.27 & -0.76 & -0.09 & 0.8 & 0.07 & 0.09 & $\mathrm{~N} / \mathrm{A}$ & 0.32 \\
\hline New Zealand & -0.23 & 0.44 & 0.24 & -0.75 & 0.38 & -0.24 & 0.59 & -0.15 & 0.54 & 0.37 \\
\hline Norway & 0.33 & -0.26 & -0.53 & 0.31 & -0.03 & -0.25 & 0.51 & -0.17 & 0.42 & -0.74 \\
\hline Poland & -0.09 & 0.25 & 0.19 & -0.94 & 0.12 & 0.5 & 0.54 & -0.46 & -0.62 & 0.2 \\
\hline Portugal & -0.4 & -0.43 & -0.72 & -0.92 & 0.04 & 0.56 & -0.02 & -0.35 & -0.54 & 0.61 \\
\hline Slovak Republic & 0.69 & 0.53 & 0.36 & -0.93 & 0.03 & -0.43 & 0.27 & 0.08 & -0.63 & 0.58 \\
\hline Spain & 0.68 & -0.22 & -0.06 & -0.96 & 0.01 & -0.01 & 0.37 & 0.1 & -0.56 & 0.31 \\
\hline Sweden & 0.42 & -0.42 & 0.47 & -0.95 & 0.02 & -0.64 & 0.13 & 0.46 & -0.44 & -0.12 \\
\hline Switzerland & 0.5 & -0.51 & -0.46 & -0.91 & -0.18 & -0.13 & 0.91 & 0.22 & -0.58 & -0.23 \\
\hline Turkey & 0.17 & 0.4 & 0.33 & -0.88 & 0.12 & 0.41 & 0.38 & 0.04 & -0.33 & 0.12 \\
\hline United Kingdom & 0.16 & -0.57 & 0.18 & -0.68 & 0.16 & 0.56 & 0.35 & -0.56 & -0.3 & -0.42 \\
\hline United States & 0.4 & -0.12 & 0.7 & -0.86 & 0.16 & 0.64 & 0.04 & -0.66 & 0.83 & -0.03 \\
\hline
\end{tabular}


Table 1. Continued. Correlation of Country GDP Difference Series with Partner Trade Balance.

Data source: SourceOECD, the OECD's Online Library of Statistical Databases, Books and Periodicals.

\begin{tabular}{|c|c|c|c|c|c|c|c|c|c|}
\hline \multicolumn{10}{|c|}{ COUNTRY } \\
\hline & Norway & Poland & Portugal & Spain & Sweden & Switzerland & Turkey & UK & US \\
\hline Start year & 1988 & 1992 & 1988 & 1988 & 1988 & 1988 & 1989 & 1988 & 1990 \\
\hline Partner country & & & & & & & & & \\
\hline Australia & 0.17 & 0.72 & -0.18 & -0.18 & 0 & 0.65 & 0.08 & -0.27 & -0.7 \\
\hline Austria & -0.39 & 0.22 & 0.17 & 0.65 & 0.16 & -0.14 & 0.46 & 0.44 & -0.1 \\
\hline Belgium-Lux. & -0.47 & 0.51 & -0.15 & 0.78 & 0.09 & 0.31 & 0.45 & 0.7 & 0.26 \\
\hline Canada & -0.7 & 0.68 & 0.3 & 0.14 & -0.31 & 0.26 & -0.37 & 0.07 & 0.4 \\
\hline Czech Republic & -0.24 & 0.5 & 0.31 & 0.07 & 0 & 0.72 & 0.57 & -0.09 & 0.19 \\
\hline Denmark & -0.49 & 0.57 & 0.35 & -0.17 & 0.06 & -0.04 & -0.75 & -0.54 & 0.27 \\
\hline Finland & -0.08 & -0.1 & 0.28 & 0.52 & -0.17 & 0.02 & 0.47 & 0.48 & 0.25 \\
\hline France & -0.62 & 0.12 & 0.2 & 0.61 & 0.07 & 0.08 & 0.16 & -0.17 & 0.57 \\
\hline Germany & -0.16 & 0.37 & 0.5 & 0.84 & 0.46 & 0.59 & 0.2 & 0.49 & 0.55 \\
\hline Greece & -0.17 & -0.49 & 0.16 & -0.69 & -0.15 & 0.57 & -0.7 & -0.42 & 0.11 \\
\hline Hungary & 0.19 & 0.82 & 0.01 & 0.64 & 0.02 & 0.11 & 0.35 & 0.69 & 0.39 \\
\hline Iceland & -0.2 & 0.28 & 0.61 & 0.04 & -0.23 & 0.68 & -0.08 & -0.16 & -0.14 \\
\hline Ireland & -0.52 & 0.1 & 0.06 & 0.76 & 0.14 & -0.31 & 0.89 & -0.59 & 0.22 \\
\hline Italy & 0.21 & 0.3 & 0.24 & 0.8 & -0.17 & -0.1 & 0.24 & 0.78 & 0.62 \\
\hline Japan & 0.07 & -0.09 & 0.32 & 0.2 & 0.09 & 0.53 & 0.33 & 0.09 & 0.61 \\
\hline Korea & 0.66 & 0.37 & 0.13 & 0.83 & 0.2 & 0.41 & 0.62 & 0.69 & 0.16 \\
\hline Mexico & 0.28 & 0.1 & 0.46 & -0.23 & -0.24 & 0.36 & -0.47 & 0.23 & 0.43 \\
\hline Netherlands & -0.62 & 0.5 & 0.59 & 0.73 & 0.16 & -0.31 & 0.14 & -0.11 & -0.66 \\
\hline New Zealand & 0.08 & -0.37 & 0.41 & 0.14 & -0.39 & -0.35 & -0.56 & 0.42 & -0.55 \\
\hline Norway & $\mathrm{N} / \mathrm{A}$ & 0.39 & 0.2 & 0.37 & 0.37 & 0.76 & 0.94 & -0.07 & 0.5 \\
\hline Poland & 0.22 & $\mathrm{~N} / \mathrm{A}$ & 0.13 & -0.48 & -0.05 & 0.55 & -0.01 & -0.26 & 0.05 \\
\hline Portugal & -0.28 & 0.66 & $\mathrm{~N} / \mathrm{A}$ & -0.65 & -0.04 & 0.11 & -0.77 & 0.62 & 0.42 \\
\hline Slovak Republic & -0.06 & 0.11 & 0.18 & -0.72 & 0.11 & 0.17 & 0.88 & -0.32 & 0.32 \\
\hline Spain & -0.15 & 0.1 & 0.25 & 0.06 & -0.4 & 0.29 & 0.22 & 0.29 & 0.49 \\
\hline Sweden & -0.3 & 0.6 & 0.11 & 0.64 & $\mathrm{~N} / \mathrm{A}$ & 0.53 & 0.24 & -0.3 & 0.51 \\
\hline Switzerland & -0.06 & 0.34 & 0.15 & 0.23 & -0.21 & $\mathrm{~N} / \mathrm{A}$ & 0.9 & 0.64 & 0.02 \\
\hline Turkey & -0.01 & -0.56 & 0.45 & -0.22 & -0.07 & 0.5 & 0.18 & 0.21 & 0.21 \\
\hline United Kingdom & -0.38 & 0.77 & -0.1 & -0.33 & -0.31 & -0.52 & -0.55 & $\mathrm{~N} / \mathrm{A}$ & 0.19 \\
\hline United States & -0.25 & 0.38 & -0.06 & -0.48 & -0.07 & 0.37 & -0.75 & -0.03 & $\mathrm{~N} / \mathrm{A}$ \\
\hline
\end{tabular}


Table 2. Cross Correlation of USA vs OECD Output Differences and Trade Balances.

Data source: SourceOECD, the OECD's Online Library of Statistical Databases, Books and Periodicals.

US GDP Change vs Country Trade Balance with US

\begin{tabular}{|c|c|c|c|c|c|c|c|c|}
\hline Time Period & & $85-90$ & $88-93$ & $91-96$ & $94-99$ & $97-02$ & $00-04$ & CUMM \\
\hline Start year & Country & & & & & & & \\
\hline 1990 & Australia & $\mathrm{N} / \mathrm{A}$ & $(0.32)$ & $(0.37)$ & $(0.11)$ & $(0.61)$ & $(0.66)$ & $(0.49)$ \\
\hline 1988 & Austria & $(0.48)$ & $(0.11)$ & 0.29 & 0.29 & $(0.45)$ & 0.48 & 0.39 \\
\hline 1985 & Belgium-Luxemburg & 0.12 & 0.38 & 0.17 & 0.41 & 0.00 & $(0.22)$ & $(0.08)$ \\
\hline 1985 & Canada & $(0.42)$ & $(0.16)$ & 0.48 & 0.52 & $(0.31)$ & 0.23 & 0.37 \\
\hline 1990 & Czech Rep. & $\mathrm{N} / \mathrm{A}$ & $\mathrm{N} / \mathrm{A}$ & 0.32 & 0.43 & $(0.22)$ & 0.38 & 0.33 \\
\hline 1988 & Denmark & $(0.16)$ & 0.02 & 0.19 & 0.30 & $(0.28)$ & $(0.11)$ & 0.26 \\
\hline 1985 & Finland & 0.30 & 0.39 & $(0.31)$ & 0.04 & $(0.06)$ & 0.05 & 0.34 \\
\hline 1985 & France & 0.04 & 0.41 & 0.53 & 0.47 & $(0.20)$ & 0.22 & 0.46 \\
\hline 1985 & Germany & $(0.04)$ & 0.19 & 0.36 & 0.49 & $(0.18)$ & 0.42 & 0.49 \\
\hline 1985 & Greece & 0.29 & 0.25 & 0.28 & 0.36 & 0.03 & $(0.78)$ & $(0.50)$ \\
\hline 1995 & Hungary & $\mathrm{N} / \mathrm{A}$ & $\mathrm{N} / \mathrm{A}$ & $\mathrm{N} / \mathrm{A}$ & $\mathrm{N} / \mathrm{A}$ & $(0.33)$ & $(0.57)$ & $(0.02)$ \\
\hline 1997 & Iceland & $\mathrm{N} / \mathrm{A}$ & $\mathrm{N} / \mathrm{A}$ & $\mathrm{N} / \mathrm{A}$ & $\mathrm{N} / \mathrm{A}$ & $(0.24)$ & $(0.30)$ & $(0.21)$ \\
\hline 1997 & Ireland & $\mathrm{N} / \mathrm{A}$ & $\mathrm{N} / \mathrm{A}$ & $\mathrm{N} / \mathrm{A}$ & $\mathrm{N} / \mathrm{A}$ & $(0.36)$ & 0.44 & 0.19 \\
\hline 1985 & Italy & $(0.16)$ & 0.04 & 0.40 & 0.43 & $(0.30)$ & 0.48 & 0.50 \\
\hline 1985 & Japan & 0.02 & 0.23 & 0.10 & 0.24 & 0.07 & $(0.15)$ & 0.37 \\
\hline 1995 & Korea & 0.27 & 0.13 & $(0.23)$ & 0.31 & $(0.30)$ & 0.14 & 0.17 \\
\hline 1993 & Mexico & $\mathrm{N} / \mathrm{A}$ & $\mathrm{N} / \mathrm{A}$ & $\mathrm{N} / \mathrm{A}$ & 0.13 & $(0.36)$ & 0.44 & 0.30 \\
\hline 1985 & Netherlands & $(0.05)$ & 0.13 & $(0.08)$ & $(0.15)$ & $(0.21)$ & $(0.16)$ & $(0.39)$ \\
\hline 1987 & New Zealand & 0.43 & 0.27 & $(0.25)$ & $(0.25)$ & $(0.30)$ & 0.36 & 0.13 \\
\hline 1985 & Norway & 0.23 & 0.17 & 0.35 & 0.32 & $(0.23)$ & $(0.01)$ & 0.41 \\
\hline 1995 & Poland & $\mathrm{N} / \mathrm{A}$ & $\mathrm{N} / \mathrm{A}$ & $\mathrm{N} / \mathrm{A}$ & $(0.11)$ & $(0.22)$ & 0.66 & 0.23 \\
\hline 1995 & Portugal & $\mathrm{N} / \mathrm{A}$ & $\mathrm{N} / \mathrm{A}$ & $\mathrm{N} / \mathrm{A}$ & 0.13 & $(0.13)$ & 0.46 & 0.32 \\
\hline 1985 & Spain & $(0.34)$ & $(0.11)$ & 0.32 & 0.01 & $(0.42)$ & 0.26 & 0.16 \\
\hline 1985 & Sweden & 0.17 & 0.43 & 0.42 & 0.45 & $(0.10)$ & 0.61 & 0.56 \\
\hline 1985 & Switzerland & $(0.29)$ & 0.06 & 0.00 & $(0.37)$ & $(0.27)$ & 0.22 & $(0.02)$ \\
\hline 1987 & Turkey & 0.17 & 0.22 & 0.16 & 0.15 & $(0.45)$ & 0.18 & 0.31 \\
\hline 1985 & UK & $(0.30)$ & $(0.16)$ & $(0.03)$ & 0.17 & $(0.07)$ & 0.46 & 0.22 \\
\hline
\end{tabular}

Country GDP Change vs US Trade Balance with Country

\begin{tabular}{|c|c|c|c|c|c|c|c|c|}
\hline Time Period & & $85-90$ & $88-93$ & $91-96$ & $94-99$ & $97-02$ & $00-04$ & CUMM \\
\hline Start year & Country & & & & & & & \\
\hline 1990 & Australia & $\mathrm{N} / \mathrm{A}$ & 0.52 & 0.62 & 0.20 & $(0.07)$ & 0.22 & 0.34 \\
\hline 1988 & Austria & 0.11 & $(0.42)$ & $(0.43)$ & $(0.40)$ & 0.13 & 0.07 & 0.00 \\
\hline 1985 & Belgium-Luxemburg & 0.07 & $(0.21)$ & $(0.08)$ & $(0.35)$ & 0.20 & 0.26 & $(0.05)$ \\
\hline 1985 & Canada & 0.22 & $(0.10)$ & $(0.47)$ & $(0.61)$ & $(0.14)$ & $(0.20)$ & $(0.39)$ \\
\hline 1990 & Czech Rep. & $\mathrm{N} / \mathrm{A}$ & $\mathrm{N} / \mathrm{A}$ & $(0.41)$ & $(0.17)$ & $(0.06)$ & $(0.21)$ & $(0.33)$ \\
\hline 1988 & Denmark & 0.27 & $(0.01)$ & $(0.10)$ & $(0.07)$ & 0.01 & $(0.15)$ & $(0.13)$ \\
\hline 1985 & Finland & $(0.37)$ & $(0.39)$ & $(0.34)$ & 0.01 & 0.18 & 0.12 & $(0.16)$ \\
\hline 1985 & France & $(0.26)$ & 0.03 & 0.29 & $(0.23)$ & 0.07 & 0.14 & $(0.13)$ \\
\hline 1985 & Germany & 0.12 & 0.21 & 0.30 & 0.03 & 0.13 & 0.17 & 0.26 \\
\hline 1985 & Greece & 0.33 & 0.35 & 0.33 & 0.20 & 0.01 & $(0.05)$ & 0.26 \\
\hline 1995 & Hungary & $\mathrm{N} / \mathrm{A}$ & $\mathrm{N} / \mathrm{A}$ & $\mathrm{N} / \mathrm{A}$ & $\mathrm{N} / \mathrm{A}$ & $(0.26)$ & $(0.24)$ & $(0.16)$ \\
\hline 1997 & Iceland & $\mathrm{N} / \mathrm{A}$ & $\mathrm{N} / \mathrm{A}$ & $\mathrm{N} / \mathrm{A}$ & $\mathrm{N} / \mathrm{A}$ & $(0.11)$ & $(0.04)$ & $(0.04)$ \\
\hline 1997 & Ireland & $\mathrm{N} / \mathrm{A}$ & $\mathrm{N} / \mathrm{A}$ & $\mathrm{N} / \mathrm{A}$ & $\mathrm{N} / \mathrm{A}$ & $(0.19)$ & $(0.02)$ & $(0.05)$ \\
\hline 1985 & Italy & 0.16 & 0.21 & 0.12 & 0.43 & 0.15 & $(0.29)$ & 0.07 \\
\hline 1985 & Japan & 0.27 & 0.34 & 0.38 & 0.39 & $(0.15)$ & $(0.30)$ & 0.48 \\
\hline 1995 & Korea & $\mathrm{N} / \mathrm{A}$ & $\mathrm{N} / \mathrm{A}$ & 0.54 & 0.21 & 0.00 & $(0.11)$ & $(0.06)$ \\
\hline 1993 & Mexico & $\mathrm{N} / \mathrm{A}$ & $\mathrm{N} / \mathrm{A}$ & $\mathrm{N} / \mathrm{A}$ & $(0.22)$ & 0.15 & 0.08 & $(0.08)$ \\
\hline 1985 & Netherlands & 0.29 & 0.23 & 0.08 & 0.13 & 0.52 & 0.58 & 0.47 \\
\hline 1987 & Zealand & 0.22 & 0.09 & 0.06 & $(0.15)$ & $(0.10)$ & $(0.12)$ & $(0.14)$ \\
\hline 1985 & Norway & $(0.06)$ & $(0.26)$ & $(0.47)$ & $(0.63)$ & $(0.36)$ & $(0.32)$ & $(0.32)$ \\
\hline 1995 & Poland & $\mathrm{N} / \mathrm{A}$ & $\mathrm{N} / \mathrm{A}$ & $\mathrm{N} / \mathrm{A}$ & 0.21 & 0.04 & $(0.16)$ & 0.09 \\
\hline 1995 & Portugal & $\mathrm{N} / \mathrm{A}$ & $\mathrm{N} / \mathrm{A}$ & $\mathrm{N} / \mathrm{A}$ & $(0.48)$ & 0.26 & 0.37 & 0.22 \\
\hline 1985 & Spain & 0.44 & 0.03 & 0.01 & 0.04 & $(0.11)$ & 0.00 & $(0.20)$ \\
\hline 1985 & Sweden & $(0.40)$ & $(0.40)$ & $(0.25)$ & $(0.48)$ & $(0.56)$ & $(0.42)$ & $(0.22)$ \\
\hline 1985 & Switzerland & 0.46 & 0.14 & 0.16 & 0.03 & 0.15 & $(0.02)$ & 0.08 \\
\hline 1987 & Turkey & 0.44 & 0.48 & $(0.16)$ & 0.01 & $(0.34)$ & $(0.22)$ & $(0.23)$ \\
\hline 1985 & UK & 0.30 & 0.20 & 0.30 & 0.23 & $(0.06)$ & $(0.45)$ & $(0.17)$ \\
\hline
\end{tabular}

